\title{
Synthesis, microstructure and mechanical properties of ceria stabilized tetragonal zirconia prepared by spray drying technique
}

\author{
S C SHARMA*, N M GOKHALE, RAJIV DAYAL and RAMJI LAL \\ Naval Materials Research Laboratory, Shil Badlapur Road, P.O. Anand Nagar, Ambernath (East), Thane 421 506, India
}

MS received 23 April 2001; revised 5 November 2001

\begin{abstract}
Ceria stabilized zirconia powders with ceria concentration varying from 6 to 16 mol\% were synthesized using spray drying technique. Powders were characterized for their particle size distribution and specific surface area. The dense sintered ceramics fabricated using these powders were characterized for their microstructure, crystallite size and phase composition. The flexural strength, fracture toughness and microhardness of sintered ceramics were measured. High fracture toughness and flexural strength were obtained for sintered bodies with $12 \mathrm{~mol} \%$ of $\mathrm{CeO}_{2}$. Flexural strength and fracture toughness were dependent on $\mathrm{CeO}_{2}$ concentration, crystallite size and phase composition of sintered bodies. Correlation of data has indicated that the transformable tetragonal phase is the key factor in controlling the fracture toughness and strength of ceramics. It has been demonstrated that the synthesis method is effective to prepare nanocrystalline tetragonal ceria stabilized zirconia powders with improved mechanical properties. $\mathrm{Ce}-\mathrm{ZrO}_{2}$ with 20 wt $\%$ alumina was also prepared with flexural strength, $1200 \mathrm{MPa}$ and fracture toughness, $9 \cdot 2 \mathrm{MPa} \sqrt{\mathrm{m}}$.
\end{abstract}

Keywords. Zirconia; ceria stabilized zirconia; nanocrystalline; spray drying; toughened ceramics; mechanical properties.

\section{Introduction}

Ceria stabilized tetragonal zirconia polycrystalline ceramics possess distinct advantages over other conventional structural ceramic materials (Garvie et al 1975; Evans and Cannon 1986) because of their better thermal stability in moist environments (Matsumato 1978), wider range of solid solubility in tetragonal region and coefficient of thermal expansion matching with that of iron alloys (Tsukuma and Shimada 1985; Nettleship and Stevens 1987). Consequently, ceria stabilized zirconia ceramics have been investigated extensively for structural applications.

The highly improved mechanical properties in these transformation toughened ceramics are related to the stress induced transformation of the metastable tetragonal grains to the monoclinic phase at the crack tips (McMeeking and Evans 1982; Chen and Reyes-Morel 1986; Hannink et al 2000). Therefore, the transformability of the metastable tetragonal phase in the process zone plays a dominant role in the ultimate attainable mechanical properties of these materials. The grain size and microstructure of these materials are difficult to control in conventional technique such as ball milling for powder preparation. The larger ball milled particles sinter at much higher temperature leading to considerable grain growth, which does not permit retention of desired tetragonal

\footnotetext{
*Author for correspondence
}

phase and high values of mechanical properties in the material (Wang et al 1992). Most of the earlier studies on $\mathrm{CeO}_{2}-\mathrm{ZrO}_{2}$ system are with powders prepared by conventional methods and the results are inconsistent due to the poor homogeneity and sinterability of the powders (Wang et al 1992). Recently few attempts have been made to prepare $\mathrm{CeO}_{2}-\mathrm{ZrO}_{2}$ using chemical methods and only a limited effort has been made to understand the effect of $\mathrm{CeO}_{2}$ content and grain size on the mechanical properties of the system (Wang et al 1992; Maschio et al 1992). Various additives and sintering aids have also been tried to improve sintered density and flexural strength of the material (Maschio et al 1998; Kojima et al 2000).

Recently high purity, chemically homogenous and reactive ceria stabilized zirconia powders have been prepared by chemical methods (Yin et al 1999; Matsui and Ohgai 1999) and sintered ceramics having considerably high density and transformable tetragonal phase have been obtained using these powders. However, little effort has been made to establish structure-property correlation in the sintered ceramics (Yoshioka et al 1992).

The objective of the present paper is, therefore, to study the effect of ceria doping on phase composition, crystallite size and mechanical properties such as flexural strength and fracture toughness of zirconia ceramics. Effort has also been made to enhance strength of Ce-TZP ceramics by incorporating $20 \mathrm{wt} \%$ alumina as a second phase (Cutler et al 1991). 


\section{Experimental}

\subsection{Preparation of powders and $\mathrm{Ce}-\mathrm{ZrO}_{2}$ ceramics}

The following raw materials were used for preparation of ceria stabilized zirconia powders: (i) $\mathrm{ZrOCl}_{2} \cdot 8 \mathrm{H}_{2} \mathrm{O}$ (IRE Ltd., 99\% purity) and (ii) ceric ammonium nitrate $(\mathrm{CDH}$, $>99 \%$ purity).

The zirconium oxychloride was recrystallized and converted into nitrate as per procedure described elsewhere (Lal et al 1993) and doped with required amounts of ceric ammonium nitrate solution to prepare composite nitrate solution of the following compositions: (i) $6 \mathrm{~mol} \%$ $\mathrm{CeO}_{2}-94 \mathrm{~mol} \% \quad \mathrm{ZrO}_{2} \quad\left(6 \mathrm{Ce}-\mathrm{ZrO}_{2}\right)$, (ii) $8 \mathrm{~mol} \% \quad \mathrm{CeO}_{2}-$ $92 \mathrm{~mol} \% \mathrm{ZrO}_{2}\left(8 \mathrm{Ce}-\mathrm{ZrO}_{2}\right)$, (iii) $10 \mathrm{~mol} \% \mathrm{CeO}_{2}-90 \mathrm{~mol} \%$ $\mathrm{ZrO}_{2}\left(10 \mathrm{Ce}-\mathrm{ZrO}_{2}\right)$, (iv) $12 \mathrm{~mol} \% \quad \mathrm{CeO}_{2}-88 \mathrm{~mol} \% \quad \mathrm{ZrO}_{2}$ $\left(12 \mathrm{Ce}-\mathrm{ZrO}_{2}\right)$, (v) $14 \mathrm{~mol} \% \mathrm{CeO}_{2}-86 \mathrm{~mol} \% \mathrm{ZrO}_{2}(14 \mathrm{Ce}-$ $\mathrm{ZrO}_{2}$ ), and (vi) $16 \mathrm{~mol} \% \mathrm{CeO}_{2}-84 \mathrm{~mol} \% \mathrm{ZrO}_{2}\left(16 \mathrm{Ce}-\mathrm{ZrO}_{2}\right)$.

The mixed solutions were spray dried in a lab model Spray Drier (Anhydro, Denmark) and calcined at $500^{\circ} \mathrm{C}$ for $4 \mathrm{~h}$. The calcined powders were deagglomerated in an attritor, mixed with binder and compacted at a hydraulic pressure of $175 \mathrm{MPa}$ followed by pressure less sintering of the compacts at $1400^{\circ} \mathrm{C}$ for $2 \mathrm{~h}$.

Alumina toughened Ce-TZP was prepared by attrition milling of $99.9 \%$ purity alumina powder with spray dried $12 \mathrm{Ce}-\mathrm{TZP}$ powder in the ratio $20: 80$ by weight. The compaction and sintering parameters were same as in case of $\mathrm{Ce}-\mathrm{ZrO}_{2}$ ceramics.

\subsection{Characterization of powders and $\mathrm{Ce}-\mathrm{ZrO}_{2}$ ceramics}

The attrited powders of $6 \mathrm{Ce}-\mathrm{ZrO}_{2}$ and $16 \mathrm{Ce}-\mathrm{ZrO}_{2}$ were characterized for their particle size distribution by laser beam diffraction technique (Mastersizer-2000, Malvern Instruments) and surface area by BET technique (Surface Area Analyser model 2200, Micromeritics Inc.) The density of sintered ceramics was measured using Archi- medes method. The microstructure was studied by SEM (Jeol, JSM-840). Sintered specimens were cut into bars of $2.5 \times 3.5 \times 30 \mathrm{~mm}^{3}$ and polished to $1 \mu \mathrm{m}$ finish using diamond paste for evaluation of mechanical properties. Flexural strength was measured by $3 \mathrm{pt}$. bend test with a span of $20 \mathrm{~mm}$ at a crosshead speed of $0.5 \mathrm{~mm} / \mathrm{min}$ and the fracture toughness was measured using SENB technique (Gokhale et al 1994). The hardness of the specimen was measured by micro indentation technique. X-ray diffraction techniques were used to determine crystallite size, compositional homogeneity and percentage of monoclinic $(m)$, transformable tetragonal $(t)$, nontransformable tetragonal $\left(t^{\prime}\right)$ and cubic $(c)$ phases in sintered ceramics. Monochromatic $\mathrm{CuK}_{\alpha}$ radiation was used in the present work. Crystallite size was calculated using the $(11 \overline{1})_{m},(111)_{m}$ and $(111)_{t}$ diffraction peaks using Scherrer formula (Klug and Alexander 1954). Compositional homogeneity of sintered ceramics was examined using a Williamson Hall plot (Osendi et al 1985) and also by EDAX analysis.

\section{Results and discussion}

SEM photomicrographs of calcined $6 \mathrm{Ce}-\mathrm{ZrO}_{2}$ and $16 \mathrm{Ce}-$ $\mathrm{ZrO}_{2}$ powders are shown in figure 1. The particle agglomerates are spherical and in the range $3-30 \mu \mathrm{m}$. Figure 2 shows the particle size distribution of the above powders. The particle size, $D_{50}$ for the powders are $5.91 \mu \mathrm{m}$ and $5.57 \mu \mathrm{m}$, respectively. It is observed that the amount of dopant (ceria concentration) has no effect on particle size distribution of zirconia powders. Similar effect has also been observed for surface area of these powders, which is in the range $50-55 \mathrm{~m}^{2} / \mathrm{g}$ for all the compositions.

The sintered density, proportions of $m, t, t^{\prime}$ and $c$ phases and crystallite size of different compositions of sintered ceramics are shown in table 1 . The sintered density of ceramics is $>98.2 \%$ except for $6 \mathrm{Ce}-\mathrm{ZrO}_{2}$. The
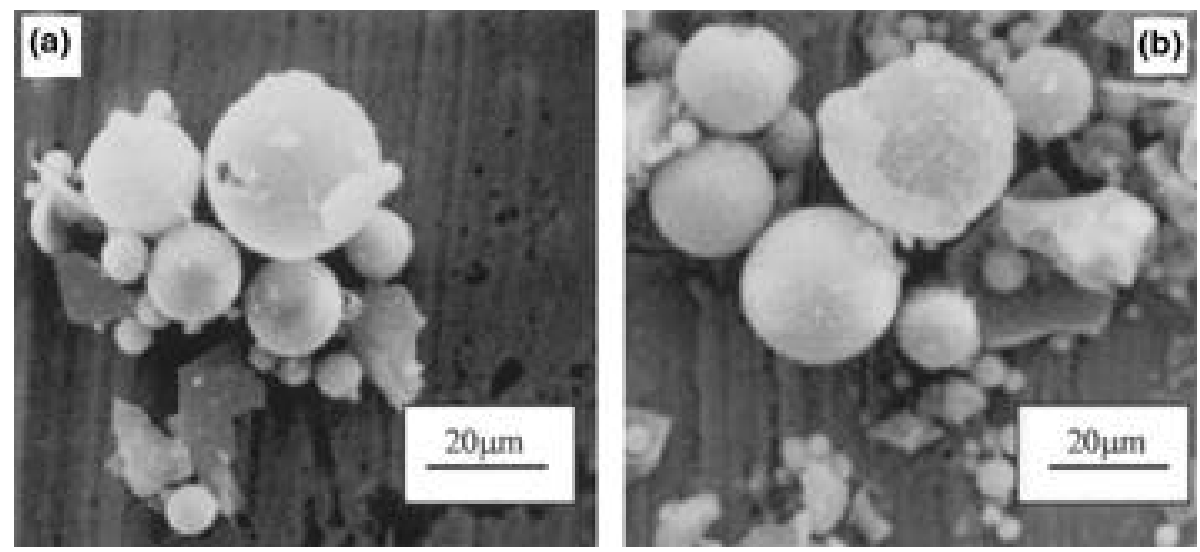

Figure 1. SEM photomicrographs of calcined ceria doped zirconia powders: (a) 6Ce$\mathrm{ZrO}_{2}$ and (b) $16 \mathrm{Ce}-\mathrm{ZrO}_{2}$. 



Figure 2. Particle size distribution of ceria stabilized zirconia powders: (a) $6 \mathrm{Ce}-\mathrm{ZrO}_{2}$ and (b) $16 \mathrm{Ce}-\mathrm{ZrO}_{2}$.

Table 1. Variation of density, crystallite size, phase composition and grain size with composition of sintered $\mathrm{Ce}-\mathrm{ZrO}_{2}$ ceramics.

\begin{tabular}{|c|c|c|c|c|c|c|}
\hline \multirow[b]{2}{*}{ Composition } & \multirow{2}{*}{$\begin{array}{c}\text { Density } \\
\text { (\% theoretical) }\end{array}$} & \multirow{2}{*}{$\begin{array}{l}\text { Crystallite } \\
\text { size }(n m)\end{array}$} & \multicolumn{3}{|c|}{ Phase composition (mol\%) } & \multirow{2}{*}{$\begin{array}{l}\text { Average grain } \\
\text { size }(\mu \mathrm{m})\end{array}$} \\
\hline & & & $m$ & $t+t^{\prime}$ & $c$ & \\
\hline $6 \mathrm{Ce}-\mathrm{ZrO}_{2}$ & $97 \cdot 05$ & $30 \cdot 0$ & 22 & $78+0$ & 0 & $2 \cdot 5$ \\
\hline $8 \mathrm{Ce}-\mathrm{ZrO}_{2}$ & $98 \cdot 26$ & $27 \cdot 1$ & 10 & $90+0$ & 0 & $2 \cdot 3$ \\
\hline $10 \mathrm{Ce}-\mathrm{ZrO}_{2}$ & $98 \cdot 42$ & $24 \cdot 0$ & 0 & $100+0$ & 0 & $2 \cdot 2$ \\
\hline $12 \mathrm{Ce}-\mathrm{ZrO}_{2}$ & $98 \cdot 60$ & $22 \cdot 5$ & 0 & $100+0$ & 0 & $2 \cdot 0$ \\
\hline $14 \mathrm{Ce}-\mathrm{ZrO}_{2}$ & $98 \cdot 60$ & $21 \cdot 3$ & 0 & $77+23$ & 0 & 1.9 \\
\hline $16 \mathrm{Ce}-\mathrm{ZrO}_{2}$ & $98 \cdot 60$ & $20 \cdot 6$ & 0 & $42+46$ & 12 & 1.9 \\
\hline
\end{tabular}


lower density is due to the higher monoclinic phase leading to development of microcracks during sintering. It may be seen that the powders containing 6 and $8 \mathrm{~mol} \%$ $\mathrm{CeO}_{2}$ contain $m+t$ phases, powders having 10,12 and $14 \mathrm{~mol} \% \quad \mathrm{CeO}_{2}$ are fully tetragonal whereas $16 \mathrm{~mol} \%$ $\mathrm{CeO}_{2}$ addition gives rise to cubic phase. The axial ratio (c/a) decreases with increase in $\mathrm{CeO}_{2}$ concentration from 6 to $16 \mathrm{~mol} \%$. The amount of metastable transformable tetragonal $(t)$ phase decreases and non-transformable tetragonal $\left(t^{\prime}\right)$ phase increases with increase in ceria concentration above $12 \mathrm{~mol} \%$. Our results are in close agreement with earlier observations (Quinelato et al 2000) for powders synthesized from polymer precursor. It has also been observed that crystallite size of zirconia ceramics decreases with increase in ceria concentration. This is in accordance with thermodynamic equation for free energy for phase transformation (Lange 1982). The ceramics with 10 and $12 \mathrm{~mol} \% \mathrm{CeO}_{2}$ exhibit maximum transformable tetragonal $(t)$ phase for a crystallite size of 24 and $22 \mathrm{~nm}$, respectively. To achieve maximum fracture toughness and strength in $\mathrm{Ce}-\mathrm{ZrO}_{2}$ the sintered ceramics should have nearly theoretical density and maximum amount of transformable tetragonal phase which is possible if the crystallite size is between 22 and $24 \mathrm{~nm}$. Figure 3 shows $\mathrm{XRD}$ patterns of sintered $6 \mathrm{Ce}-\mathrm{ZrO}_{2}, 12 \mathrm{Ce}-\mathrm{ZrO}_{2}$ and $16 \mathrm{Ce}-\mathrm{ZrO}_{2}$ ceramics taken at room temperature. The (400) reflections exhibit 4 peaks for two types of tetragonal phases, transformable $t$ phase (at $2 \theta=72.90^{\circ}$, $74.36^{\circ}$ ) and non-transformable $t^{\prime}$ phase (at $2 \theta=73.42^{\circ}$, $74.16^{\circ}$ ) with axial ratio $(c / a) 1.017$ and 1.008 , respectively. The Williamson Hall plots obtained from data of these XRD patterns is shown in figure 4. The slopes of the curves are zero which shows the absence of lattice strain and thereby confirms the compositional homogeneity of the material. The amount of $\mathrm{Ce}$ in $12 \mathrm{Ce}-\mathrm{ZrO}_{2}$ powders has been found to be $12.65 \pm 0.2 \mathrm{wt} \%$ by EDAX analysis which is in close agreement with the actual $13.0 \mathrm{wt} \%$ added during preparation.

Figure 5 shows variation of hardness, flexural strength and SENB fracture toughness of sintered ceramics with

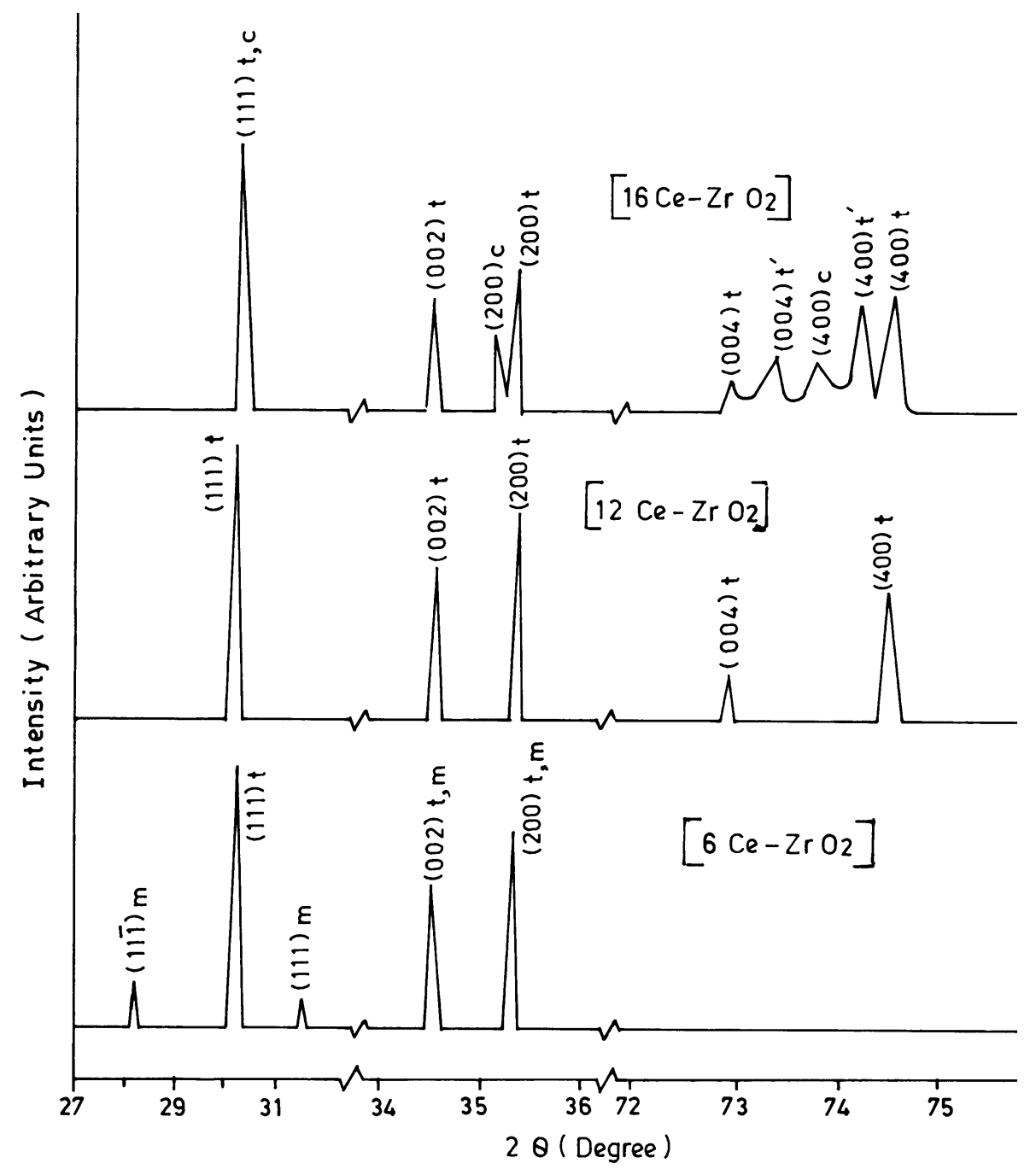

Figure 3. XRD patterns of ceria stabilized zirconia ceramics. 


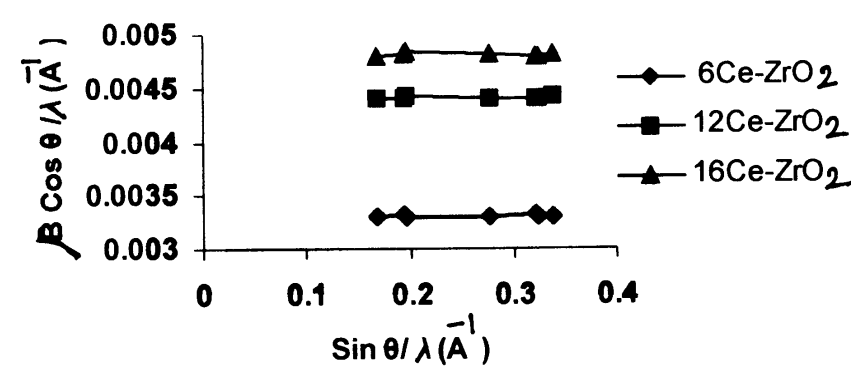

Figure 4. Williamson Hall plot for ceria stabilized zirconia ceramics.

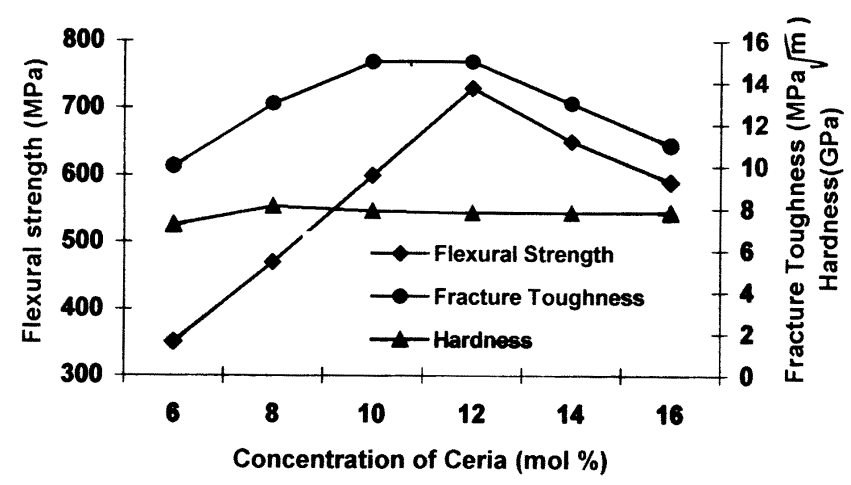

Figure 5. Variation of mechanical properties with ceria concentration in zirconia ceramics.

amount of $\mathrm{CeO}_{2}$ in zirconia. It may be seen that the flexural strength and fracture toughness increase sharply with increase in ceria concentration up to $12 \mathrm{~mol} \%$ and start decreasing slowly with further increase in ceria concentration. This may be attributed to increase in transformable tetragonal phase in the material up to $12 \mathrm{~mol} \%$ $\mathrm{CeO}_{2}$ concentration and thereafter decrease in transformable tetragonal phase and increase in non transformable tetragonal phase with further increase in ceria concentration. The similar trend in values of flexural strength and fracture toughness signifies that flexural strength is controlled by stress induced transformation toughening and flaw size in the sintered ceramics is very small which can be attributed to high purity, fine and homogeneous powders prepared using spray drying technique. The transformable tetragonal $(t)$ phase and consequently the flexural strength and fracture toughness are maximum at a critical crystallite size of $\sim 22 \mathrm{~nm}$. The material with lower crystallite size does not transform to monoclinic phase in the stress field of a propagating crack thereby reducing the fracture toughness as well as strength of the material. With crystallite size above the critical value, the $t$ phase transforms spontaneously to monoclinic phase without absorption of energy at the crack tip leading to lower fracture toughness. The flexural strength (730 MPa) and fracture toughness $(15 \mathrm{MPa} \sqrt{\mathrm{m}})$ achieved in the present work using spray dried powder are higher than the

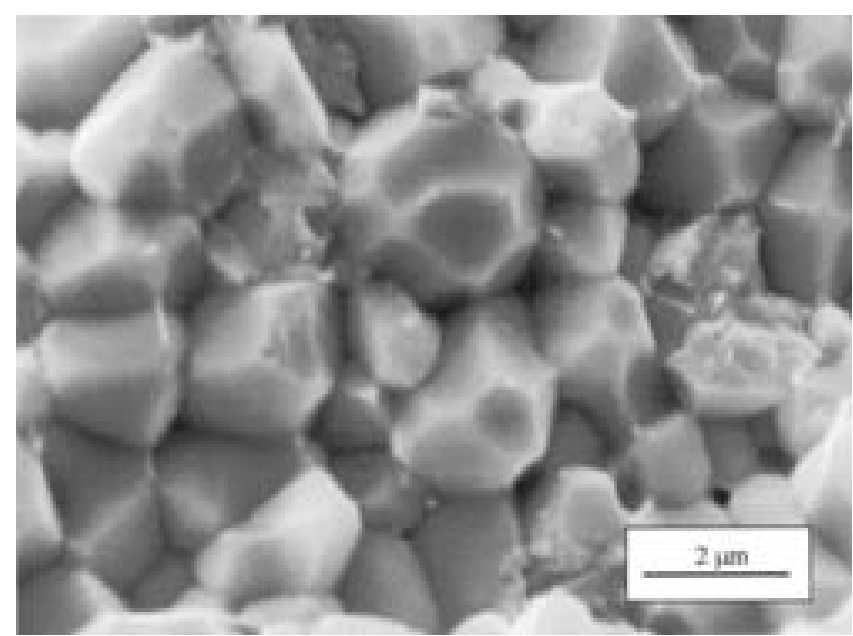

Figure 6. SEM photomicrograph of ceria stabilized zirconia ceramics.

earlier reported values (Tsukuma and Shimada 1985; Chen and Brook 1989; Wang et al 1992; Quinelato et al 2000).

The variation of ceria content in zirconia has very little effect on the hardness of $\mathrm{Ce}-\mathrm{ZrO}_{2}$. The hardness of $6 \mathrm{Ce}-$ $\mathrm{ZrO}_{2}$ has been found to be slightly lower due to its lower density and microcracks. SEM photomicrograph of sintered $12 \mathrm{Ce}-\mathrm{ZrO}_{2}$ ceramics is shown in figure 6 . The average grain size was about $2 \mu \mathrm{m}$. The lower grain size and high density of ceramics in the present studies may be attributed to fine starting powders and lower sintering temperature. The finer grains have vital role in achieving higher flexural strength in the present study. The data generated in the present study are useful in developing material with desired mechanical strength by controlling the crystallite size and optimizing the concentration of ceria in $\mathrm{ZrO}_{2}$. The addition of $20 \mathrm{wt} \%$ alumina in $12 \mathrm{Ce}-\mathrm{TZP}$ gives the much improved strength $(1200 \mathrm{MPa})$ with moderate toughness $(9.2 \mathrm{MPa} \sqrt{\mathrm{m}})$ as compared to earlier study (Cutler et al 1991). Thus the properties similar to Y-TZP ceramics can also be achieved in Ce-TZP by alumina addition with added advantage of low temperature thermal stability.

\section{Conclusions}

In the present study a correlation between microstructure and mechanical properties of $\mathrm{Ce}-\mathrm{ZrO}_{2}$ has been carried out. It has been demonstrated that high purity, fine and chemically homogeneous powders can be prepared by spray drying technique. These powders can be sintered by pressureless sintering at $1400^{\circ} \mathrm{C}$. It has been demonstrated that the volume fraction of metastable transformable tetragonal phase is dependent on ceria concentration. Fracture toughness and strength increase with increase in the amount of transformable tetragonal phase in the ceramics. The excellent mechanical properties of ceramics 
are attributed to the fine, spherical and reactive starting powders with good compositional homogeneity.

\section{Acknowledgement}

The authors are thankful to Dr P C Deb, Director, NMRL, for his keen interest in the work.

\section{References}

Chen I W and Reyes-Morel P E 1986 J. Am. Ceram. Soc. 69 181

Chen Y L and Brook R 1989 J. Br. Ceram. Trans. J. 887

Cutler R A, Mayhew R J, Prettyman K M and Virkar A V 1991 J. Am. Ceram. Soc. 74179

Evans A G and Cannon R M 1986 Acta Metall. 34761

Garvie R C, Hannink R H J and Pascoe R T 1975 Nature 258 703

Gokhale N M, Dayal R, Sharma S C and Lal R 1994 J. Mater. Sci. 295709

Hannink R H J, Kelly P M and Muddle B C 2000 J. Am. Ceram. Soc. $\mathbf{8 3} 461$
Klug H P and Alexander L E 1954 X-ray diffraction procedures (New York: Wiley) Ch. 9

Kojima T, Sakamato W, Yogo T, Fuji T and Hirano S $2000 \mathrm{~J}$. Am. Ceram. Soc. 83281

Lal R, Sharma S C and Dayal R 1993 Ferroelectrics 141165

Lange F F 1982 J. Mater. Sci. 17225

Maschio S, Sbaizero O and Meriani S 1992 J. Euro. Ceram. Soc. 9127

Maschio S, Pezzotto G and Sbaizero O 1998 J. Euro. Ceram. Soc. 181979

Matsui K and Ohgai M 1999 J. Am. Ceram. Soc. 823017

Matsumato R K 1978 J. Am. Ceram. Soc. 71 C128

McMeeking R and Evans A G 1982 J. Am. Ceram. Soc. 65242

Nettleship I and Stevens R 1987 Int. J. High Tech. Ceram. 31

Osendi M I, Moya J S, Serna C J and Soria J 1985 J. Am. Ceram. Soc. 68135

Quinelato A L, Longo E, Perzolli L A and Varela J A $2000 \mathrm{~J}$. Eur. Ceram. Soc. 201077

Tsukuma K and Shimada M 1985 J. Mater. Sci. 201178

Wang J, Zheng X H and Stevens R 1992 J. Mater. Sci. 275348

Yin S, Uchida S, Fujishiro Y, Ohmori M and Sato T $1999 \mathrm{Br}$. Ceram. Trans. J. 9819

Yoshioka T, Dosaka K, Sato T, Okuwaki S, Tanno S and Miura T 1992 J. Mater. Sci. Lett. 1161 